\title{
Quiste de primer arco branquial, reporte de caso y revisión de la literatura
}

\author{
First branchial arch cyst, case report and review of the literature \\ Macarena Karle $\mathbf{P}^{1}$, María José Yumha $\mathrm{L}^{2}$, Paul Boettiger $\mathbf{B}^{1}$, Francisco Carrasco $\mathrm{F}^{3}$, \\ Ricardo Zamorano $\mathbf{S}^{1,3}$.
}

\begin{abstract}
RESUMEN
Los quistes branquiales de primer arco son una malformación congénita de baja frecuencia. Se desarrollan por la fusión incompleta de la hendidura faríngea entre el primer y el segundo arco branquial. Pueden permanecer silentes por mucho tiempo y manifestarse cuando se sobreinfectan, causando significativa morbilidad. Por lo general, se presentan en la infancia, pero muchas veces su diagnóstico es tardío ya que son difíciles de diferenciar de adenopatías u otras masas, debiendo ser considerados dentro del diagnóstico diferencial de masa cervical y parotídea, especialmente en pacientes jóvenes. La cirugía es el tratamiento definitivo, requiriendo una escisión completa del quiste y su trayecto fistuloso para evitar las recurrencias. Debido a su localización intraparotídea y complejidad morfológica, es necesario conocer la anatomía en detalle para evitar lesionar el nervio facial. En esta revisión, se pretende presentar las características clínicas y resultados quirúrgicos en una paciente lactante con diagnóstico de quiste de primer arco, así como efectuar una revisión de la literatura.
\end{abstract}

Palabras clave: Quiste de primer arco branquial, masa cervical lateral, fístula cutánea.

\begin{abstract}
First branchial arch cysts are very infrequent congenital malformations. Their development is due to an incomplete fusion of the pharyngeal cleft between the first and second branchial arch. They can remain silent for a very long time and manifest when they become infected, causing significant morbidity. In general, they present in childhood, but many times its diagnosis occurs on a late onset since they are difficult to differentiate from lymphadenopathies or other masses. So, they should be considered on the differential diagnosis of cervical and parotid masses, especially in young patients. Surgery is its definitive treatment. Complete excision of the cyst and its fistula must be performed to avoid recurrences. Due to its intraparotid localization and morphological
\end{abstract}

\footnotetext{
Médico Servicio de Otorrinolaringología, Hospital Clínico Universidad de Chile.

2 Interna de Medicina, Facultad de Medicina, Universidad de Chile.

3 Otorrinolaringólogo Servicio de Otorrinolaringología, Hospital Gustavo Fricke.
} 
complexity it is necessary to understand the anatomy in detail to avoid facial nerve lesions. In this revision, we aim to present clinical characteristics and surgical outcomes in an infant with the diagnosis of first branchial arch cyst and to review the literature.

Key words: First branchial arch cyst, lateral cervical mass, cutaneous fistula.

\section{INTRODUCCIÓN}

Las anomalías branquiales de primer arco constituyen una malformación congénita infrecuente. Representan entre 1\%-8\% del total de las malformaciones branquiales ${ }^{1}$. Se desarrollan por la fusión incompleta de la hendidura faríngea entre el primer y el segundo arco branquial' ${ }^{2}$ La alteración puede originarse en cualquier nivel a lo largo del tracto embrionario residual de la primera hendidura branquial. Dicha hendidura se extiende desde el conducto auditivo externo, a través de glándula parótida hacia el triángulo submandibular. Por lo tanto, la lesión se localiza cercana a ésta glándula y al oído externo ${ }^{3}$. Considerando la región anatómica descrita, generalmente se expresan como un aumento de volumen cervical unilateral con o sin fístula, también pudiendo manifestarse con secreción en distintas localizaciones dependiendo del sitio de apertura fistular o como una cicatriz eccematosa en la zona ${ }^{4}$. Se subdividen, según Olsen ${ }^{1}$ en tres grandes grupos: fístulas, quistes y senos, siendo estos últimos los más frecuentes. Por lo general, se presentan en la infancia, pero muchas veces su diagnóstico es tardío porque son difíciles de diferenciar de adenopatías u otras masas cervicales, confundiéndose con adenitis cervicales, quistes dermoides, hemangiomas y linfangiomas entre otros ${ }^{5}$. Se ha descrito una tardanza en el diagnóstico de aproximadamente 3,5 años promedio desde el inicio de los síntomas ${ }^{6}$. No existe una evidencia clara sobre la distribución por sexos en anomalías de arco branquial, habiéndose encontrado sin diferencia significativa en las revisiones de Olsen ${ }^{1}$ y Guo ${ }^{7}$, pero sí, con una proporción de 2:1 de predominio en el sexo femenino en la efectuada por Triglia ${ }^{6}$. Es común que se sobreinfecten, causando significativa morbilidad. Si bien su presentación es en general aislada ${ }^{6}$, se han descrito asociados a otras malformaciones locales como microtia, estenosis del conducto auditivo externo (CAE), colesteatoma congénito y absceso posauricular ${ }^{8}$, así como también síndromes con múltiples alteraciones derivadas del primer 0 segundo arco tales como el síndrome de Treacher Collins, el síndrome de Pierre Robin, el síndrome de Goldenhar ${ }^{9} y$, menos comúnmente, el síndrome de ojo de gato ${ }^{10}$, entre otros.

La evaluación diagnóstica con imágenes es complementaria. En el enfrentamiento inicial se realiza ecografía que ayuda a dilucidar entre los distintos diagnósticos diferenciales, constituyendo la modalidad de imágenes de elección en la evaluación de masas congénitas en niños. Puede agregarse tomografía computarizada (TC), resonancia nuclear magnética (RNM), fistulografía, entre otros, para confirmar y evaluar la extensión de la lesión ${ }^{11}$. El tratamiento definitivo de la lesión es la escisión quirúrgica completa ${ }^{6}$. La recurrencia de la lesión se asocia a resección inadecuada de ésta. Mientras más intervenciones se realicen, mayor susceptibilidad del nervio facial de ser dañado tanto directa como indirectamente por la cicatrización y fibrosis del tejido aledaño, por lo que se destaca la importancia de una resección adecuada en una instancia quirúrgica' ${ }^{12}$.

A continuación, se presentan las características clínicas y resultados de una cirugía, de muy baja frecuencia, en una paciente lactante con diagnóstico de quiste de primer arco branquial.

\section{CASO CLÍNICO}

Paciente de sexo femenino de 1 año y 7 meses de edad, quien consulta por una historia clínica de 7 meses de evolución caracterizada por la aparición de un orificio fistuloso en mejilla izquierda con salida de exudado purulento constante que provoca maceración de la piel vecina, siendo sometida a múltiples tratamientos antibióticos y curaciones sin respuesta favorable (Figura 1). Se realiza estudio con ecografía y TC de cuello que informan lesión quística parotídea con trayecto fistuloso hacia el conducto auditivo externo concordante con el diagnóstico de quiste branquial de primer arco 


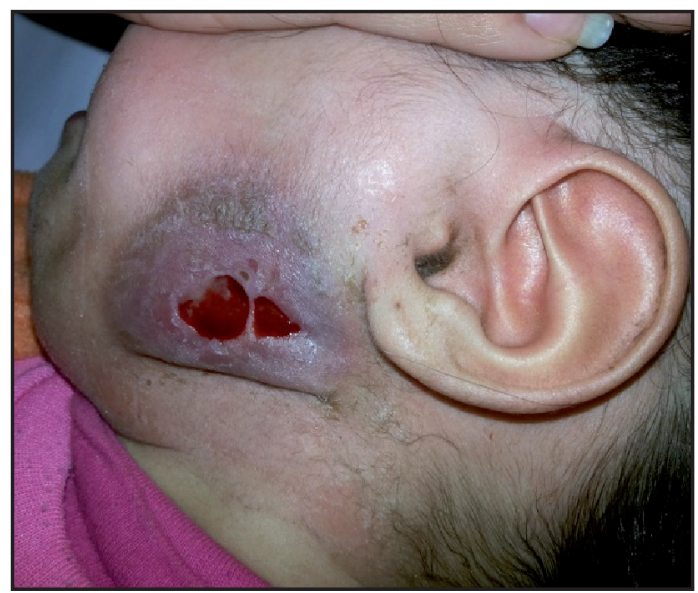

Figura 1. Presentación clínica inicial.

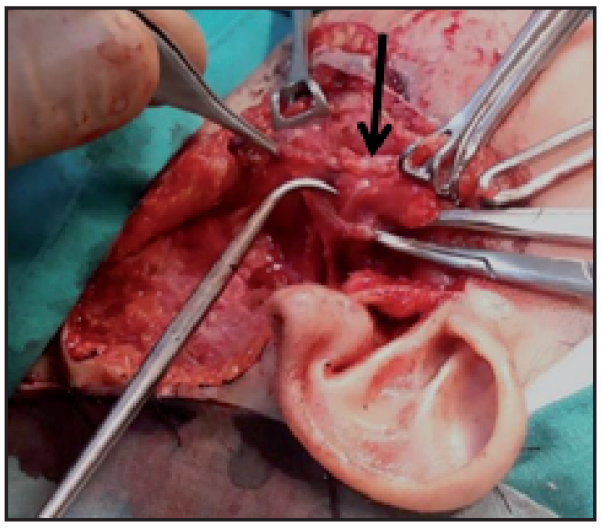

Figura 2. Rama cervicofacial del nervio facial en íntimo contacto con trayecto fistuloso.

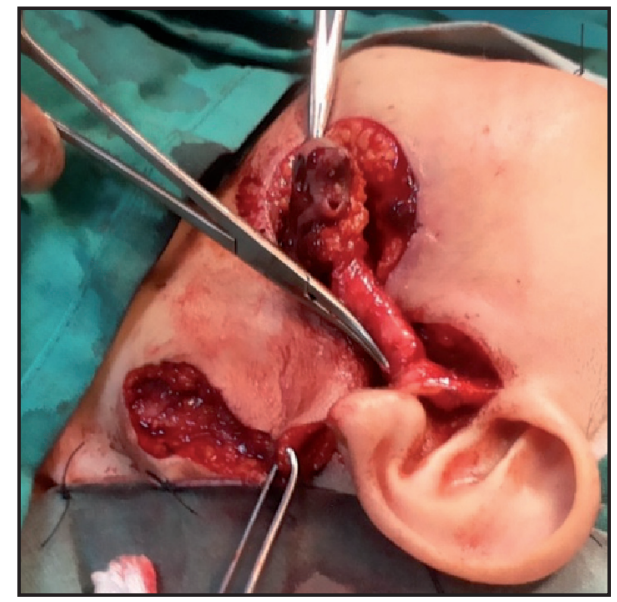

Figura 3. Resección completa de fístula que llegaba hasta región tragal, preservando la función del nervio facial. fistulizado. Se decide resección quirúrgica de la fístula bajo visión microscópica para evitar lesionar el nervio facial (Figuras 2-3) el que estaba en íntimo contacto con la lesión, manteniéndose finalmente, indemne (Figura 4). Actualmente, al año y medio de evolución, la paciente no ha presentado recurrencia de enfermedad.

\section{DISCUSIÓN}

Las anomalías de primer arco branquial son poco comunes. A lo largo del tiempo, se han clasificado de distintas formas, destacando la de Work ${ }^{13}$ en

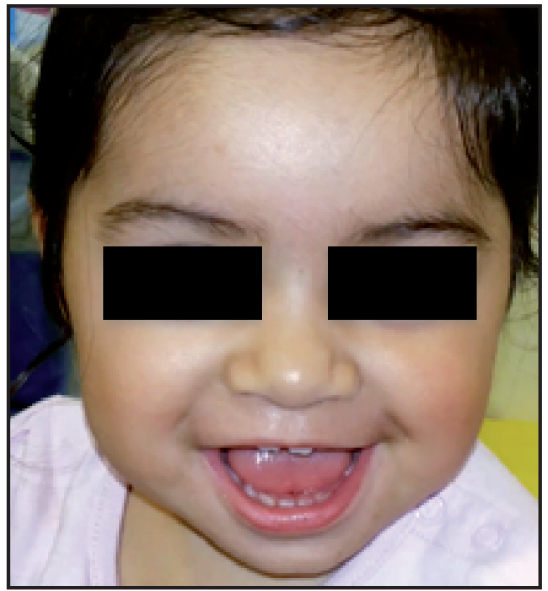

Figura 4. Nervio facial indemne. 
1972, quien describe un tipo I y II según morfología e histopatología. Existe una mayor prevalencia de las lesiones tipo II, descritas como aquellas que representan una duplicación de la porción cartilaginosa y membranosa del conducto auditivo externo (CAE). Contienen piel, anexos y cartílago, pudiendo estar en relación con la glándula parótida. Se asocian frecuentemente a fístulas. Según lo detallado, nuestra paciente presentaría la versión más común, presentándose la lesión asociada a una fístula que desembocaba superior al hueso hiodes. Además, se describe que este tipo (tipo II de Work) es más común en niños pequeños, concordando con este caso clínico presentado ${ }^{14}$.

Cuando nos enfrentamos a pacientes con este tipo de lesión, es necesario agotar los recursos diagnósticos para poder resolverlo con la mayor información posible. El diagnóstico preoperatorio de estas anomalías no es certero, siendo importante descartar alguna lesión subyacente que cambie el pronóstico y manejo del paciente ${ }^{15}$. Si bien, en nuestro caso, el cuadro clínico inicial sugirió un trayecto fistuloso en la zona correspondiente al primer arco branquial, fue necesaria la evaluación con imágenes. Iniciamos el estudio con una ecografía de partes blandas que aludió la presencia de un trayecto fistuloso que se originaba en la glándula parótida. Luego, una TC confirmó la extensión de la lesión. Respecto a la utilidad de la RNM, Sahu ${ }^{16}$ discute que puede brindar mayores ventajas para la evaluación de anomalías de primer arco branquial tipo I y de segundo arco branquial, ya que brinda una mejor caracterización de la relación entre la masa y el tejido glandular circundante. Se fundamenta la importancia del apoyo imagenológico en la diferenciación de los diversos diagnósticos que podrían confundirnos y retrasar el actuar óptimo en la resolución final de esta u otras patologías.

$\mathrm{Si}$ bien sabemos que el manejo definitivo de estos pacientes requiere cirugía, actualmente no existe consenso sobre ciertos aspectos de la resección. Por ejemplo, desconocemos la edad óptima para realizarla, si es que la hay. Guo, en su revisión, respecto a las anomalías de primer arco branquial y su relación con el nervio facial, recomienda para proteger la indemnidad del nervio, realizar la intervención quirúrgica en pacientes mayores de 4 años, considerando que el nervio estaría más robusto y podría soportar mejor la manipulación.
Además, separa a los pacientes según la clasificación de Work y, aquellos catalogados de tipo Work II, tienen mayor asociación con profundidad de la fístula respecto al nervio (sin ser determinante, ya que es una clasificación histológica a la cual no todos los pacientes tuvieron acceso) ${ }^{7}$. D'Souza plantea en su revisión una posible asociación entre la edad del paciente y la relación entre el trayecto de la fístula y el nervio. Menciona que a menor edad del paciente existiría una relación más íntima entre ambas estructuras anatómicas, con mayor frecuencia de fístulas en aquellos trayectos que se encuentran profundos al nervio 0 abrazan sus ramas ${ }^{17}$. Sin embargo, nuestra paciente poseía síntomas y signos difíciles de controlar. Someterla al tiempo de espera podría haberla perjudicado aún más que exponerla a un daño potencial iatrogénico del nervio. Por otro lado, Ertas, sugiere una asociación entre la localización de la porción cutánea de la fístula (sobre o bajo la rama mandibular) con la del nervio (medial o lateral al trayecto fistuloso) ${ }^{18}$. No existiendo un acuerdo en este tema, es mandatorio realizar la búsqueda minuciosa del nervio facial, y su relación con la lesión, antes del abordaje quirúrgico, enfatizando la importancia del complemento imagenológico. Se requieren más estudios para poder comparar la resolución temprana con el planteamiento de esperar para proteger al nervio. Este dilema revela la importancia de presentar este caso, en quien su temprana edad genera importante dificultad en la evaluación y determinación del manejo definitivo.

\section{CONCLUSIÓN}

Los quistes de primer arco branquial son malformaciones de baja frecuencia. Por 10 general, permanecen silentes por mucho tiempo y suelen manifestarse cuando se sobreinfectan. Es importante considerarlos dentro del diagnóstico diferencial de una masa cervical y parotídea, especialmente en pacientes jóvenes.

La cirugía es el tratamiento definitivo y se debe realizar una escisión completa del quiste y su trayecto fistuloso para evitar la recurrencia. Debido a su localización intraparotídea y complejidad morfológica, es necesario conocer la anatomía en detalle para evitar lesionar el nervio facial. Actualmente, 
no existe consenso sobre la edad óptima para realizar la resección. Por esta razón, consideramos importante la presentación de este caso clínico, planteando la dificultad de la decisión de intervención quirúrgica a edad temprana.

\section{BIBLIOGRAFÍA}

1. Olsen KD, Maragos NE, Weiland LH. First branchial cleft anomalies. Laryngoscope 1980; 90: 423-36.

2. Finn D, Buchalter I, Sarti E, Romo T, Chodosh P. First branchial cleft cysts: clinical update. Laryngoscope 1987; 97: 136-40.

3. Gilabert R, Berenguer B, González B, Marín C, de Tomás E, Buitrago G, et al. Quiste de primer arco branquial intraparotídeo: complejo proceso diagnóstico y terapéutico. Cir Pediatr 2013; 26: 44-7.

4. Maddy E, Ashram Y. First branchial cleft anomalies: presentation, variability and safe surgical management. Eur Arch Otorhinolaryngol 2013; 270(6): 197-25.

5. Navarro M, Mínguez N, Rodríguez F. Fístula laterocervical izquierda de tercer arco branquial: Caso clínico. Rev Otorrinolaringol Cir Cabeza Cuello [online]. 2013, vol.73, n.1 [citado 2015-0630], pp. 79-82. Disponible en: <http://www.scielo. $\mathrm{cl} /$ scielo.php?script=sci_arttext\&pid=S071848162013000100013\&lng=es\&nrm=is0>. ISSN 0718-4816. http://dx.doi.org/10.4067/S071848162013000100013.

6. Triglia JM, Nicollas R, Ducroz V, Koltai PJ, Garabedian EN. First branchial cleft anomalies: a study of 39 cases and a review of the literature. Arch Otolaryngol Head Neck Surg 1998; 124(3): 291-5.

7. Guo Y, Guo C. Relation between a first branchial cleft anomaly and the facial nerve. $\mathrm{Br} J$ Oral Maxillofac Surg 2012; 50: 259-63.
8. Abdollah S, Naderpoor M, Mousviagdas M. First branchial cleft fistula associated with external auditory canal stenosis and middle ear cholesteatoma. Iran J Otorhinolaryngol 2014; 26(77): 263-6.

9. Johnson JM, Moonis G, Green GE, Carmody R, BRUBANK HN. Syndromes of the first and second branchial arches, part 2: syndromes. AJNR2011; 32: 230-7.

10. Avior G, Derowe A, Fliss DM, Leicear-Trejo L, BrAvERMAN I. Associated branchial cleft anomalies in the cat eye syndrome. Harefuah 2007; 146(2): 99-101, 166-7.

11. Vázquez E, Enríquez G, Castellote A et al. US, CT, and MR imaging of neck lesions in children. Radiographics 1995; 15: 105-22.

12. Waldhausen JH. Branchial cleft and arch anomalies in children. Semin Pediatr Surg 2006; 2: 64-9.

13. Work WP. Newer concept of first branchial cleft defects. Laryngoscope 1972; 9: 1581-93.

14. Sichel JY, Halperin D, Dano I, Dangoor E. Clinical update on type II first branchial cleft cysts. Laryngoscope 1998; 108: 1524-7.

15. Guldfred L, Philipsen B, Simm C. Branchial cleft anomalies: accuracy of preoperative diagnosis, clinical presentation and management. $J$ Laryngol Otol 2012; 126: 598-604.

16. Sahu S, Kumar A, Ramakrishnan TS. Branchial fistula: an imaging perspective. MJAFI2011;67: 262-4.

17. D'Souza AR, Uppal HS, De R, Zeitoun H. Updating concepts of first branchial cleft defects: a literature review. Int J Pediatr Otorhinolaryngol 2002; 62(2); 103-9.

18. Ertas B, Gunaydin R, Unal 0. The relationship between the fistula tract and the facial nerve in type II first branchial cleft anomalies. Auris Nasus Larynx 2015; 42 (2): 119-22. 